\title{
Electrical and dielectric analysis of phosphate based glasses doped with alkali oxides
}

\author{
M.P.F. Graça ${ }^{\text {a,* }}$, B.M.G. Melo ${ }^{\text {a }}$, P.R. Prezas ${ }^{a}$, M.A. Valente ${ }^{a}$, F.N.A. Freire ${ }^{b}$, L. Bih $^{\text {c }}$ \\ a Physics Department (I3N), Aveiro University, Campus Universitário de Santiago, Aveiro, Portugal \\ b Mechanics Engineering Department, Ceará Federal University, Fortaleza, Brazil \\ c Equipe Physico-Chimie la Matière Condensée, Faculté des Sciences de Meknès, Meknès, Morocco
}

\section{A R T I C L E I N F O}

\section{Article history:}

Received 7 April 2015

Received in revised form 7 July 2015

Accepted 8 July 2015

Available online 15 July 2015

\section{Keywords:}

Phosphate glasses

Hydrogen absorption

Differential thermal analysis

Electrical measurements

Raman spectroscopy

X-ray powder diffraction

\begin{abstract}
A B S T R A C T
In this work, new phosphate glasses with the molar composition $20.7 \mathrm{P}_{2} \mathrm{O}_{5}-17.2 \mathrm{Nb}_{2} \mathrm{O}_{5}-13.8 \mathrm{WO}_{3}-34.5 \mathrm{~A}_{2} \mathrm{O}-$ $13.8 \mathrm{~B}_{2} \mathrm{O}_{3}$ where $\mathrm{A}=\mathrm{Li}$, Na and $\mathrm{K}$ were prepared using the melt quenching technique. These types of glasses have potential to absorb hydrogen in its structure, which makes them promising materials to be used as electrolytes in intermediate temperature fuel cells. Additionally, niobium phosphate glasses can also have applications such as glass fibers, optical lenses, hermetic sealing and electrodes. The structure of the obtained samples was analyzed using Differential Thermal Analysis (DTA), X-ray powder diffraction (XRD), and Raman spectroscopy and the morphology by Scanning Electron Microscopy (SEM). The DTA measurements revealed values of glass transition temperature around $415^{\circ} \mathrm{C}$, and the Raman analysis showed that the amount of alkali and niobium oxides included on the studied compositions, successfully disrupted the P-O-P chains characteristic of the phosphate glasses. Dc $\left(\sigma_{\mathrm{dc}}\right)$ and ac $\left(\sigma_{\mathrm{ac}}\right)$ conductivities and dielectric spectroscopy measurements were performed as function of the temperature $(200-370 \mathrm{~K})$ which presented conductivity predominantly ionic $\left(\sigma_{\text {electronic }} / \sigma_{\text {ionic }}\right.$ of about $\left.10^{-4}\right)$. The dielectric spectroscopy was measured in the frequency range $100-1 \mathrm{MHz}$.
\end{abstract}

(c) 2015 Elsevier Ltd. All rights reserved.

\section{Introduction}

The fundamental building element of the phosphate glasses is a $\mathrm{PO}_{4}$ tetrahedron with one of the four oxygen atoms doubly bonded to the phosphorus atom. The structure of these glasses can be described as a network of $\mathrm{PO}_{4}$ structural units linked by covalent bonding of corner shared oxygen atoms, referred to as bridging oxygen (BO) [1,2]. The addition of network modifying oxides in the glass, leads to the disruption of the phosphate $\mathrm{P}-\mathrm{O}-\mathrm{P}$ chains, and subsequent formation of nonbridging oxygen ions (NBOs) $[1,2]$. Therefore, the linked phosphate tetrahedra can have three, two, one or zero bridging oxygen ions. The various tetrahedra which result from this classification are labeled using the $\mathrm{Q}^{\mathrm{n}}$ terminology, where $\mathrm{n}$ represents the number of $\mathrm{BO}$ s per $\mathrm{PO}_{4}$ tetrahedron $[1,2]$. The isolated $\mathrm{PO}_{4}$ tetrahedra $\mathrm{Q}^{0}$ are named orthophosphate, $Q^{1}$ pyrophosphate, $Q^{2}$ metaphosphate and the $Q^{3}$ groups with three bridging and one terminal oxygen ( $\mathrm{P}=\mathrm{O}$ bond) are named ultraphosphate $[1,2]$. Besides breaking the $\mathrm{P}-\mathrm{O}-\mathrm{P}$ linkages and creating NBOs, the addition of metal oxides can provide ionic cross-linking between NBOs, therefore increasing the bond strength of this ionic cross-link and improving the mechanical strength and chemical durability of the glasses [3].

\footnotetext{
* Corresponding author.

E-mail address: mpfg@ua.pt (M.P.F. Graça).
}

The development of highly efficient fuel cells is one of the most promising applications for hydrogen usage. Currently, proton-conducting polymer electrolyte membrane fuel cells are used for temperatures below $100{ }^{\circ} \mathrm{C}$, and solid oxide fuel cells for temperatures between 800 and $1000{ }^{\circ} \mathrm{C}$ [4]. Intermediate temperature fuel cells, remains a subject under improvement, since new materials able to be efficiently used as electrolytes between temperatures of $200-500{ }^{\circ} \mathrm{C}$ are still needed. Glass materials are stable in this range of temperatures and have an open structure with no grain boundaries, which makes them good candidates to this application [5].

Some studies $[5,6]$ have reported that phosphate glasses that incorporate tungsten oxide have the ability to absorb hydrogen protons in their structure. This capability results from the trapping of an electron by the $\mathrm{W}^{6+}$ ions which induces $\mathrm{W}^{5+}$ states and promotes the dissociation of the hydrogen atom and the adsorption of its proton. The absorption of the $\mathrm{H}^{+}$happens when the proton diffuses to the glass structure and bonds with the non-bridging oxygen ions in the matrix. Therefore, the study of new phosphate glass systems thermally stable in temperatures between 200 and $500{ }^{\circ} \mathrm{C}$, with reduced electronic conductivity and with a large number of non-bridging oxygen in their structure, is a topic of extensive consideration.

The improvement of the chemical stability also stimulates the usage of these glasses in fields such as fast ionic conductors, photonic materials and rare-earth ion host solid state lasers [3,7]. Furthermore, 
niobium phosphate glasses can have related applications such as glass fibers, optical lenses, hermetic sealing and electrodes [3,7].

Boron oxide $\left(\mathrm{B}_{2} \mathrm{O}_{3}\right)$ is also a well-known glass network former. However, the current model for the structure of vitreous boric oxide, differs significantly from the one related with silicate or phosphate glasses. $\mathrm{B}_{2} \mathrm{O}_{3}$ glass is assumed to consist of a random three-dimensional network of nearly flat $\mathrm{BO}_{3}$ triangles with a high fraction of six membered boroxol rings $[8,9]$. These structural units are connected by oxygen atoms allowing the $\mathrm{B}-\mathrm{O}-\mathrm{B}$ angle to vary, and the twisting out of the plane of the boroxol group to occur [10].

The formation of these boroxol groups can be primarily supported by the observation of a sharp band at $808 \mathrm{~cm}^{-1}$ in the Raman spectrum of the glasses [10]. When network modifiers like alkali oxides, are added to a borate glass, boron atoms change from triangular to tetrahedral coordination until it reached some critical concentration of $\mathrm{BO}_{4}$ tetrahedra. Further addition of this alkali oxide causes the formation of nonbridging oxygen $[8,9]$.

For an $\mathrm{A}_{2} \mathrm{O}-\mathrm{B}_{2} \mathrm{O}_{3}$ binary glass system $(\mathrm{A}=\mathrm{Li}, \mathrm{Na}, \mathrm{K}, \mathrm{Rb}, \mathrm{Cs})$ this process occurs approximately linearly up to $\mathrm{A}_{2} \mathrm{O} / \mathrm{B}_{2} \mathrm{O}_{3} \approx 0.5[8,9]$. The association of these $\mathrm{BO}_{3}$ and $\mathrm{BO}_{4}$ units promotes the formation of slightly more complex structural groups, composed by the cross-linking of these 3 - and 4-fold coordination boron atoms. Some of these structural units are the diborate, triborate, tetraborate and pentaborate groups, while the chain-type metaborate, ring-type metaborate, orthoborate and boroxol ring groups are exclusively formed by $\mathrm{BO}_{3}$ units $[8,9]$.

Many physical properties of these binary alkali borate glasses change through maximum/minimum when the molar percentage of the alkali oxide is about $16 \%$ [ $8-10]$. This peculiar phenomenon is also observed on more complex borate glass systems, and on glasses that combine $\mathrm{B}_{2} \mathrm{O}_{3}$ with another glass network former. This behavior is known as the boron oxide anomaly [8-10]. The presence of a minimum in the thermal expansion of these glasses has been considered as a result of a competition between the formation of the three-dimensional $\mathrm{BO}_{4}$ units (which decrease the expansion coefficient), and the introduction of the modifier ions which increase it $[8,9]$.

Besides the former network oxides, the studied compositions incorporate $\mathrm{Nb}_{2} \mathrm{O}_{5}$ and $\mathrm{WO}_{3}$ which are classified as incipient glass network formers. This means that, although they do not readily form glass, they are able to do so when mixed with a proper amount of $\mathrm{A}_{2} \mathrm{O}$ $(\mathrm{A}=\mathrm{Li}, \mathrm{Na}, \mathrm{K})$ modifier oxides. Usually, niobium and tungsten are located in octahedral sites in phosphate glasses, although there might also occur formation of some $\mathrm{MO}_{4}$ structural units $(\mathrm{M}=\mathrm{Nb}, \mathrm{W})$ [3]. The ability and portion of $\mathrm{WO}_{3}$ that can be included in the glasses, depend on the respective glass former. While $\mathrm{WO}_{3}$ can act as a nucleating agent in silicate glasses, for germanate, tellurite and borate glasses it is possible to include large amounts of $\mathrm{WO}_{3}$ in their composition. For alkali phosphate glasses, large amounts of $\mathrm{WO}_{3}(>60 \mathrm{~mol} \%$ ) can also be added without devitrification [11]. The addition of $\mathrm{WO}_{3}$ improves the thermal stability and chemical resistance against atmospheric moisture [11].

In the present work, glasses with molar compositions $20.7 \mathrm{P}_{2} \mathrm{O}_{5^{-}}$ $17.2 \mathrm{Nb}_{2} \mathrm{O}_{5}-13.8 \mathrm{WO}_{3}-34.5 \mathrm{~A}_{2} \mathrm{O}-13.8 \mathrm{~B}_{2} \mathrm{O}_{3}$, where $\mathrm{A}=\mathrm{Li}, \mathrm{Na}$, and $\mathrm{K}$ were prepared by the melt-quenching technique. The samples were analyzed using X-ray diffraction, differential thermal analysis, Raman spectroscopy and scanning electron microscopy (SEM). The electric and dielectric spectroscopy measurements were related to the sample microstructure properties.

\section{Experimental}

\subsection{Sample preparation}

Functional glasses with molar composition $20.7 \mathrm{P}_{2} \mathrm{O}_{5}-17.2 \mathrm{Nb}_{2} \mathrm{O}_{5}-$ $13.8 \mathrm{WO}_{3}-34.5 \mathrm{~A}_{2} \mathrm{O}-13.8 \mathrm{~B}_{2} \mathrm{O}_{3}$, where $\mathrm{A}=\mathrm{Li}, \mathrm{Na}$, and $\mathrm{K}$ were prepared by melt quenching technique, using high purity chemicals (>99\%) $\mathrm{P}_{2} \mathrm{O}_{5}, \mathrm{Nb}_{2} \mathrm{O}_{5}, \mathrm{WO}_{3}, \mathrm{~A}_{2} \mathrm{CO}_{3}$ and $\mathrm{B}_{2} \mathrm{O}_{3}$ in powder form. The reagents, in the appropriate amounts were mixed for $30 \mathrm{~min}$ in a Fritsch Pulverisette
5 agate ball-mixing planetary system, in order to improve the homogeneity of the mixtures.

Afterwards, the mixtures were melted at $1150{ }^{\circ} \mathrm{C}$ in alumina crucibles with a closed lid, for about $15 \mathrm{~min}$. After $7 \mathrm{~min}$ at $1150{ }^{\circ} \mathrm{C}$, and for each composition, the crucible was manually stirred in order to homogenize the melt. The complete loss of carbonates was confirmed from the Raman results which reported no vibrations related to $\mathrm{CO}_{3}^{2-}$ groups.

The melts were poured into a stainless steel slab which was immediately introduced in a furnace pre-heated at $300{ }^{\circ} \mathrm{C}$. The samples were then maintained at $300^{\circ} \mathrm{C}$ for about $12 \mathrm{~h}$, in order to improve the glasses mechanical stability by relieving internal stresses. The annealing temperature of the glasses was chosen according the author's previous work [12] on glasses with similar compositions. The compositions containing $\mathrm{Na}_{2} \mathrm{O}$ and $\mathrm{K}_{2} \mathrm{O}$ promoted the formation of transparent glasses, whereas the composition with $\mathrm{Li}_{2} \mathrm{O}$ resulted in a white opaque sample. The samples identification and the respective molar composition are indicated in the Table 1.

\subsection{Structural and morphological characterization}

The X-ray diffraction patterns (XRD) were obtained at room temperature on an Philips X'Pert MPD difractometer (CuK $\alpha$ radiation, $\lambda=$ $1.54056 \AA$ ) operating at $45 \mathrm{kV}$, and $40 \mathrm{~mA}$, with a curved graphite monochromator, an automatic divergence slit, a progressive receiving slit and a flat plane sample holder in a Bragg-Brentano parafocusing configuration. The acquisition was performed using a scan step of $0.02^{\circ}$ in $1 \mathrm{~s}$ in the $2 \theta$ angle range of $10-60^{\circ}$. Room temperature Raman spectroscopy was carried out in a Jobin Yvon HR 800 spectrometer, using the excitation line of $532 \mathrm{~nm}$. The spectra were obtained in a back-scattering geometry, between 100 and $1100 \mathrm{~cm}^{-1}$.

The morphology of the glasses was observed by scanning electron microscopy (SEM), performed in a Hitachi S4100-1 system, on the free surface of the glasses. All samples were covered with carbon before microscopic observation. The measurements were conducted in a high vacuum environment, using a beam accelerating voltage of $25 \mathrm{kV}$ and working distances between 5 and $15 \mathrm{~mm}$. Energy dispersive X-ray spectroscopy (EDS) was also performed by using a Bruker EDS spectrometer.

\subsection{Differential thermal analysis}

For the Differential Thermal Analysis, the samples were accurately weighed ( $40 \mathrm{mg}$ ) and placed in an alumina crucible $\left(\mathrm{Al}_{2} \mathrm{O}_{3}\right)$ which is thermally inert in the temperature range examined. As inert reference was used $40 \mathrm{mg}$ of alumina powder.

The glass transition temperature ( $\mathrm{Tg}$ ) and crystallization temperature (Tc) of the samples were determined using a Linseis apparatus. The heating was performed at a rate of $10{ }^{\circ} \mathrm{C}$ per minute in air conditions.

A second measurement with a different heating rate $\left(15^{\circ} \mathrm{C} / \mathrm{min}\right)$ was done to evaluate the existence of significant changes on the DTA spectra. Since this secondary measurement showed no meaningful differences, the authors chose not to include them in the present paper.

\subsection{Electrical and dielectric characterization}

For the electrical measurements the samples were polished until a thickness of about one millimeter and parallel faces were achieved. The electrodes were formed by painting both sides of the polished

Table 1

Molar composition of the prepared glasses.

\begin{tabular}{lllllrrr}
\hline \multicolumn{7}{l}{ Molar composition (\%) } \\
\hline & $\mathrm{P}_{2} \mathrm{O}_{5}$ & $\mathrm{Nb}_{2} \mathrm{O}_{5}$ & $\mathrm{WO}_{3}$ & $\mathrm{~B}_{2} \mathrm{O}_{3}$ & $\mathrm{Li}_{2} \mathrm{O}$ & $\mathrm{Na}_{2} \mathrm{O}$ & $\mathrm{K}_{2} \mathrm{O}$ \\
\hline Glass A-Li & 20.7 & 17.2 & 13.8 & 13.8 & 34.5 & 0.0 & 0.0 \\
Glass A-Na & 20.7 & 17.2 & 13.8 & 13.8 & 0.0 & 34.5 & 0.0 \\
Glass A-K & 20.7 & 17.2 & 13.8 & 13.8 & 0.0 & 0.0 & 34.5 \\
\hline
\end{tabular}




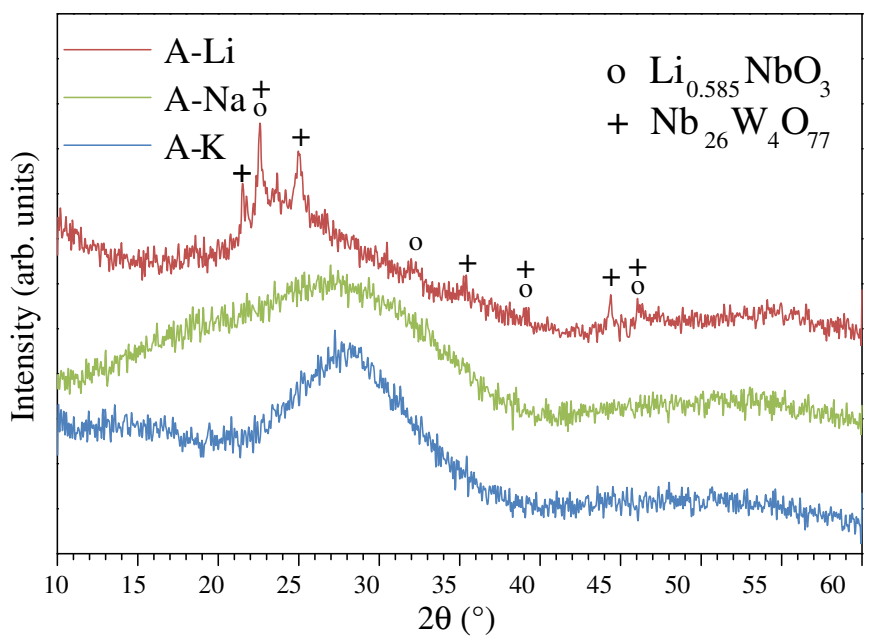

Fig. 1. XRD patterns of all the samples.

samples with silver conductive paste. With this geometry, it is valid to consider the samples as parallel plate capacitors, and consequently to apply well known equations to determine the complex permittivity $[13,14]$. For each sample, the thickness was measured at ten different points using an electronic digital caliper (accuracy of $0.01 \mathrm{~mm}$ ), and determined its average value.

The dc electrical conductivity $\left(\sigma_{\mathrm{dc}}\right)$ of the samples was measured with a Keithley 617 electrometer, capable of measuring currents down to $10^{-14} \mathrm{~A}$. This measurement was performed in a temperature range between 200 and $370 \mathrm{~K}$, using a nitrogen bath cryostat setup. During the measurements, the samples were kept in a helium atmosphere to minimize thermal gradients. The ac electrical conductivity $\left(\sigma_{\mathrm{ac}}\right)$ and impedance measurements were also performed in the temperature range of 200 to $370 \mathrm{~K}$, using the same bath cryostat, with a Network Analyzer, Agilent 4294, operating between $100 \mathrm{~Hz}$ and $1 \mathrm{MHz}$ in the $\mathrm{C}_{\mathrm{p}}-\mathrm{R}_{\mathrm{p}}$ configuration (capacitance in parallel with resistance). In both measurements, dc and ac, the temperature of the samples was controlled by an Oxford Research IT-C4 and measured using a platinum sensor. The activation energy $\left(E_{a}\right)$ of the dc and ac conductivities was evaluated in the high temperature range, by fitting the data according the Arrhenius model (Eq. (1)) [15-17]:

$\sigma=\sigma_{0} \exp \left(-\frac{E_{a}}{K_{B} T}\right)$

where $\sigma_{0}$ is a pre-exponential factor, $\mathrm{E}_{\mathrm{a}}$ the activation energy, $\mathrm{k}_{\mathrm{B}}$ the Boltzmann constant and $\mathrm{T}$ the temperature. Using this model, $\mathrm{E}_{\mathrm{a}}$ can be calculated from the slope of $\ln \left(\sigma_{\mathrm{dc}}\right)$ versus $1 / \mathrm{T}$.

The real and complex parts of the permittivity were calculated using the relations (2) and (3) [15,16]:

$\varepsilon^{\prime}=\frac{\mathrm{d} C_{\mathrm{p}}}{\mathrm{A}} \frac{\varepsilon_{0}}{\varepsilon_{0}}$

$\varepsilon^{\prime \prime}=\frac{\mathrm{d}}{\mathrm{A}} \frac{1}{\omega \mathrm{R}_{\mathrm{p}} \varepsilon_{0}}$

with $C_{p}$ and $R_{p}$ representing respectively, the measured capacitance and resistance, $\mathrm{d}$ the sample thickness, $A$ the electrode area and $\varepsilon_{0}$ the vacuum permittivity $\left(8.8542 \times 10^{-12} \mathrm{~F} / \mathrm{m}\right)$.

The ac conductivity, $\sigma_{\mathrm{ac}}$, was calculated using the relation (4) [15-17]:

$\sigma_{\mathrm{ac}}=\varepsilon^{\prime \prime} \omega \varepsilon_{0}$ where $\omega$ is the angular frequency, and $\varepsilon^{\prime \prime}$ is the imaginary part of the complex permittivity. To determine the ac activation energy $\left(E_{a}(a c)\right.$ ) these results were adjusted using the Arrhenius expression, as previously described for the $\mathrm{E}_{\mathrm{a}}(\mathrm{dc})$ (see Eq. (1)).
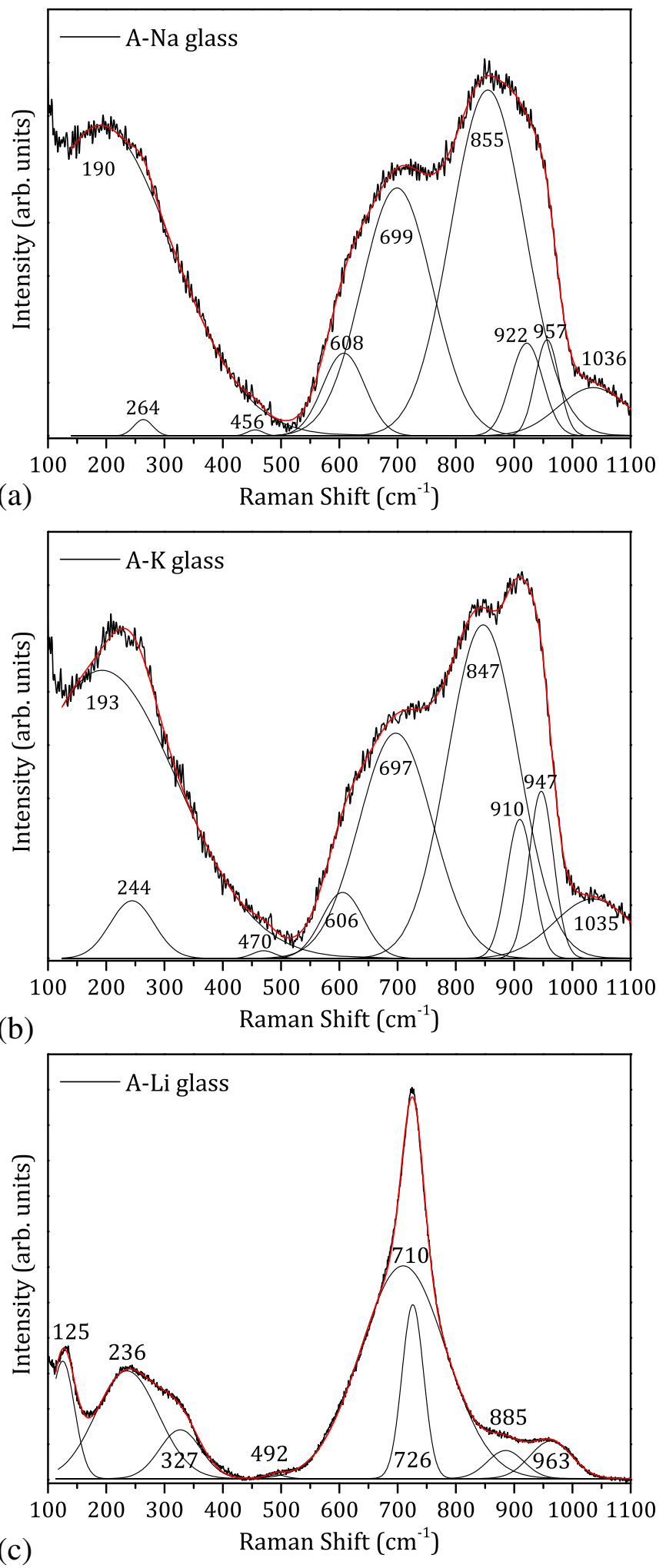

Fig. 2. Raman spectra obtained at room temperature of the A-Li (a) A-Na (b) and A-K (c) glasses. 
Table 2

Raman band positions $\left(\mathrm{cm}^{-1}\right)$ and assignment of the vibrational modes of the $\mathrm{A}-(\mathrm{Na}, \mathrm{K})$ samples. Where $v=$ stretching, $\mathrm{s}=$ symmetric and $\delta=$ bending.

\begin{tabular}{|c|c|c|c|}
\hline \multicolumn{2}{|c|}{ BBand position $\left(\mathrm{cm}^{-1}\right)$} & \multirow[t]{2}{*}{ Assignment } & \multirow[t]{2}{*}{ References } \\
\hline A-Na & A-K & & \\
\hline 190 & 193 & $\delta(\mathrm{P}-\mathrm{O}-\mathrm{P})$ & {$[21]$} \\
\hline 264 & 244 & $\delta(\mathrm{O}-\mathrm{P}-\mathrm{O})$ in $\mathrm{PO}_{4}$ units and/or $\delta(\mathrm{O}-\mathrm{Nb}-\mathrm{O})$ in $\mathrm{NbO}_{6}$ & {$[22-24,22,24,25]$} \\
\hline 456 & 470 & Overlapping of $\mathrm{M}-\mathrm{O}$ vibrations in $\mathrm{MO}_{6}[\mathrm{M}=\mathrm{W}, \mathrm{Nb}]$ & [5] \\
\hline 608 & 606 & Coupling of stretching and vibrations modes $v_{\mathrm{s}}(\mathrm{Nb}-\mathrm{O})+\delta(\mathrm{O}-\mathrm{P}-\mathrm{O})$ & {$[3,22]$} \\
\hline 699 & 697 & $v_{\mathrm{s}}(\mathrm{P}-\mathrm{O}-\mathrm{P})$ of $\mathrm{BOs}$ in pyrophosphate units & {$[27,37]$} \\
\hline 855 & 847 & $v(\mathrm{Nb}-\mathrm{O})$ in distorted $\mathrm{NbO}_{6}$ and/or $\delta(\mathrm{Nb}-\mathrm{O}-\mathrm{P}-\mathrm{O}-\mathrm{Nb})$ & {$[24,29-31,24,29]$} \\
\hline 922 & 910 & $\mathrm{~B}-\mathrm{O}-\mathrm{B}$ and $\mathrm{B}-\mathrm{O}^{-}$vibrations of orthoborate groups with $\mathrm{BO}_{3}$ structure & {$[32-34]$} \\
\hline 957 & 947 & $v_{\mathrm{s}}\left(\mathrm{P}-\mathrm{O}^{-}\right)$of NBOs in orthophosphate units and/or $v\left(\mathrm{~W}-\mathrm{O}^{-}\right.$and $\left.\mathrm{W}=0\right)$ in $\mathrm{WO}_{4}$ tetrahedra & {$[39,47,11,35,36]$} \\
\hline 1036 & 1035 & $v_{\mathrm{s}}\left(\mathrm{P}-\mathrm{O}^{-}\right)$of $\mathrm{NBOs}$ in pyrophosphate units & {$[1,5,24,37]$} \\
\hline
\end{tabular}

\section{Results and discussion}

\subsection{Structural characterization}

As shown in Fig. 1, the XRD patterns of the glasses A-(Na, K) did not revealed any discrete or sharp diffraction peaks, but broad bands, characteristic of amorphous materials. The XRD spectrum of the A-Li sample exhibits however, the presence of crystalline phases besides the amorphous phase. Namely, $\mathrm{Nb}_{26} \mathrm{~W}_{4} \mathrm{O}_{77}$ with a monoclinic crystalline structure and a secondary crystalline phase $\mathrm{Li}_{0.585} \mathrm{NbO}_{3}$ with cubic crystal system. This fact leads to the conclusion that the composition of the A-Li sample is out of the glass forming region of this system.

Fig. 2 shows the Raman spectra of the samples. For the A-Na and A-K glasses, the obtained Raman scattering is practically identical and the assignment of the vibrational modes (Table 2) is comparable for both samples. The planar carbonate ion $\left(\mathrm{CO}_{3}^{2-}\right)$ is known to have four fundamental vibration modes: a symmetric stretching vibration, an out-of-plane bend, a doubly degenerate asymmetric stretch and another doubly degenerate bending mode $[18,19]$. These vibrations occur between 700 and $1500 \mathrm{~cm}^{-1}$. Usually, a strong Raman mode around $1100 \mathrm{~cm}^{-1}$ related to the symmetric stretching vibration identifies the presence of carbonate groups $[18,20]$. The Raman spectra of the samples did not reveal evidence of this strong Raman band, neither of any vibrational mode with wavenumbers higher than $1100 \mathrm{~cm}^{-1}$. Therefore, the samples spectra at higher wavenumbers was excluded, and one can say that the melting time of the samples was sufficient to ensure the complete loss of carbonates.

The bands centered at lower wave numbers can be related to network bending modes, more precisely, the band at $190 \mathrm{~cm}^{-1}$ is assigned to $\delta(\mathrm{P}-\mathrm{O}-\mathrm{P})[21]$, the band at $260 \mathrm{~cm}^{-1}$ to $\delta(\mathrm{O}-\mathrm{P}-\mathrm{O})$ of $\mathrm{PO}_{4}$ units [22-24] and/or $\delta(\mathrm{O}-\mathrm{Nb}-\mathrm{O})$ of $\mathrm{NbO}_{6}$ units $[22,24,25]$ and

Table 3

Raman band positions $\left(\mathrm{cm}^{-1}\right)$ and assignment of the vibrational modes of the A-Li sample. Where $v=$ stretching, $\mathrm{s}=$ symmetric and $\delta=$ bending.

\begin{tabular}{|c|c|c|}
\hline $\begin{array}{l}\text { Band position } \\
\left(\mathrm{cm}^{-1}\right)\end{array}$ & Assignment & References \\
\hline \multicolumn{3}{|l|}{ A-Li } \\
\hline 125 & $\begin{array}{l}\delta(\mathrm{P}-\mathrm{O}-\mathrm{P}) \text { and/or } \delta(\mathrm{O}-\mathrm{W}-\mathrm{O}) \text { or } \delta(\mathrm{O}-\mathrm{Nb}-\mathrm{O}) \\
\text { from } \mathrm{W} / \mathrm{NbO}_{6} \text { units }\end{array}$ & {$[21,3]$} \\
\hline 236 & $\begin{array}{l}\delta(\mathrm{O}-\mathrm{P}-\mathrm{O}) \text { from } \mathrm{PO}_{4} \text { units and/or } \delta(\mathrm{O}-\mathrm{Nb}-\mathrm{O}) \text { in } \\
\mathrm{NbO}_{6}\end{array}$ & {$[22-24,22,24,25]$} \\
\hline 327 & $\begin{array}{l}\delta(\mathrm{O}-\mathrm{P}-\mathrm{O}) \text { from metaphosphate groups and/or } \\
\text { bending related with } \mathrm{WO}_{6} \text { structural units }\end{array}$ & {$[38,39]$} \\
\hline 492 & $\begin{array}{l}\text { Overlapping of } \mathrm{M}-\mathrm{O} \text { vibrations in } \mathrm{MO}_{6}[\mathrm{M}=\mathrm{W} \text {, } \\
\mathrm{Nb}]\end{array}$ & [5] \\
\hline 710 & $v_{\mathrm{s}}(\mathrm{P}-\mathrm{O}-\mathrm{P})$ of $\mathrm{BOs}$ in pyrophosphate units & {$[27,37]$} \\
\hline 726 & $\begin{array}{l}\mathrm{B}-\mathrm{O}-\mathrm{B} \text { vibrations related with chain-type } \\
\text { metaborate groups }\left(\mathrm{BO}_{3} \text { units }\right)\end{array}$ & {$[32,40]$} \\
\hline 885 & $\begin{array}{l}v(\mathrm{Nb}-\mathrm{O}) \text { in distorted } \mathrm{NbO}_{6} \text { and/or } \\
\delta(\mathrm{Nb}-\mathrm{O}-\mathrm{P}-\mathrm{O}-\mathrm{Nb})\end{array}$ & {$[24,29-31,24,29]$} \\
\hline 963 & $\begin{array}{l}v_{\mathrm{s}}\left(\mathrm{P}_{-} \mathrm{O}^{-}\right) \text {of } \mathrm{NBO} \text { in orthophosphate units } \\
\text { and/or } v\left(\mathrm{~W}-\mathrm{O}^{-} \text {and } \mathrm{W}=\mathrm{O}\right) \text { in } \mathrm{WO}_{4} \text { tetrahedra }\end{array}$ & {$[39,47,11,35,36]$} \\
\hline
\end{tabular}
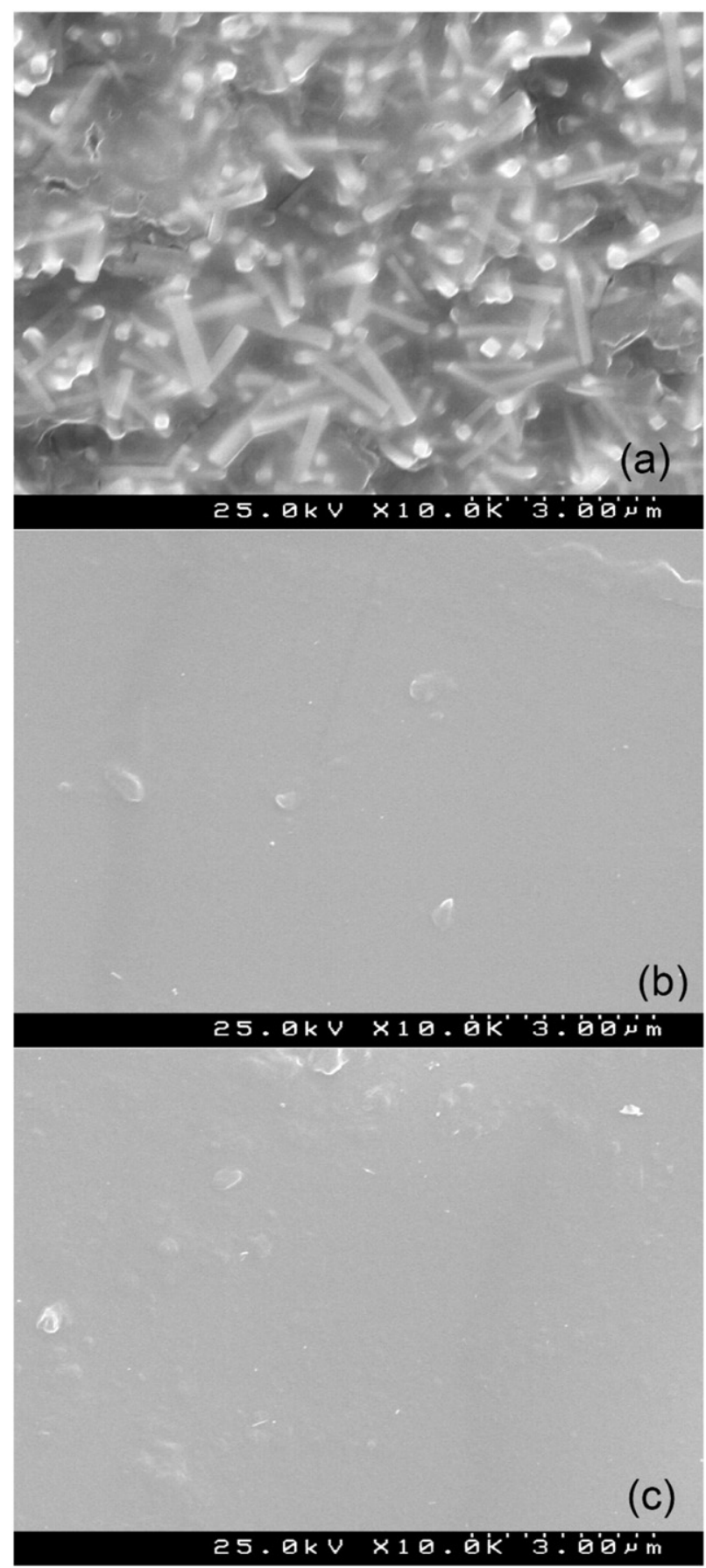

Fig. 3. SEM micrograph of the A-Li (a), A-Na (b) and A-K (c) glass surfaces. 


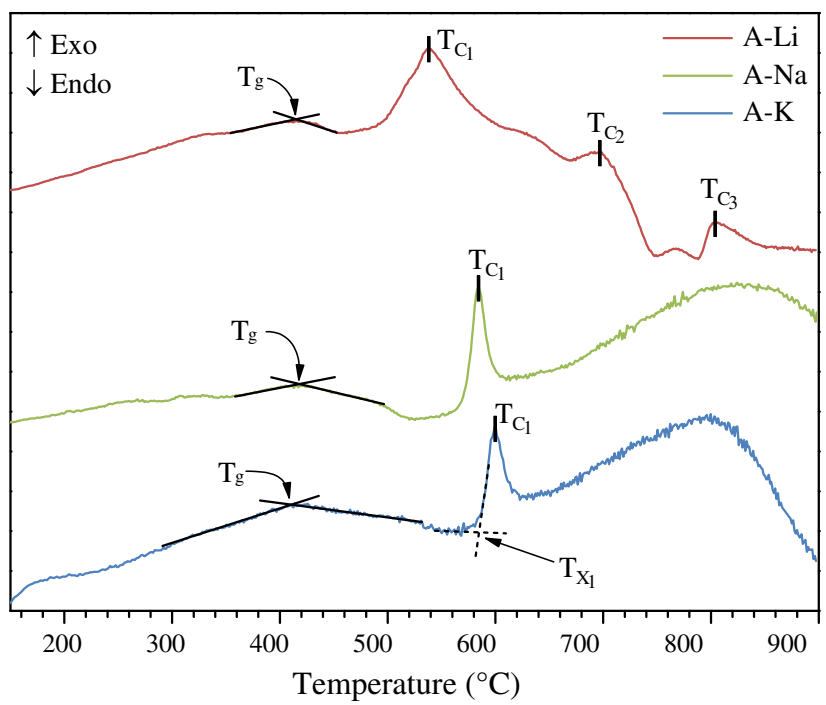

Fig. 4. DTA curves of the A-( Li, Na, K) glasses.

at $460 \mathrm{~cm}^{-1}$ there is a small band that might be associated with overlapping vibrations of $\mathrm{M}-\mathrm{O}$ bonds in the distorted $\mathrm{MO}_{6}$ octahedral units $(\mathrm{M}=\mathrm{W}, \mathrm{Nb})[5]$.

The band at $608 \mathrm{~cm}^{-1}$ is assigned to the vibrational coupling of $[(\mathrm{Nb}-\mathrm{O})$ (medium $\mathrm{Nb}-\mathrm{O}$ distances) $+(\mathrm{O}-\mathrm{P}-\mathrm{O})]$ stretching with deformation modes [3,22], while the band centered at $699 \mathrm{~cm}^{-1}$ can be attributed to $v_{s}(\mathrm{P}-\mathrm{O}-\mathrm{P})$ in pyrophosphate units $\left(\mathrm{Q}^{1}\right)$ [26-28].

The most intense part of the spectrum $\left(800-1000 \mathrm{~cm}^{-1}\right)$ is due to the overlapping of three bands. The biggest contribution is given by the band centered at $855 \mathrm{~cm}^{-1}$ that can be related to stretching of $\mathrm{Nb}$ and its neighboring NBOs in $\mathrm{NbO}_{6}$ distorted octahedra (niobium as network modifier) [24,29-31] and/or to vibrations $\delta(\mathrm{Nb}-\mathrm{O}-\mathrm{P}-\mathrm{O}-\mathrm{Nb})$ where niobium acts as glass network former $\left(\mathrm{NbO}_{4}\right.$ structural units) $[24,29]$. The other two bands that form the overlapped band are at $922 \mathrm{~cm}^{-1}$ due to $\mathrm{B}-\mathrm{O}-\mathrm{B}$ and $\mathrm{B}-\mathrm{O}$ vibrational modes in orthoborate groups of $\mathrm{BO}_{3}$ triangular units [32-34], and at $957 \mathrm{~cm}^{-1} v_{\mathrm{s}}\left(\mathrm{P}_{-} \mathrm{O}^{-}\right)$terminal bonds in isolated tetrahedral $\left(\mathrm{Q}^{0}\right)$ and/or due to $\mathrm{W}^{-} \mathrm{O}^{-}$and $\mathrm{W}=\mathrm{O}$ vibrations in $\mathrm{WO}_{4}$ tetrahedra $[11,35,36]$. These last two bands have a slightly bigger contribution in the A-K spectrum, suggesting a larger formation of these structural units for this composition.

Finally, the band near the region of $1035 \mathrm{~cm}^{-1}$, is frequently associated with the presence of symmetric stretching vibration of non-bridging oxygen in $\mathrm{Q}^{1}$ units $[1,5,24,37]$. Based on the vibrational modes discussed, and analyzing the Raman spectra, we can conclude that the inclusion of the alkali oxides and $\mathrm{Nb}_{2} \mathrm{O}_{5}$, inhibited the formation of long phosphate chains and hence, promoted the formation of a large number of non-bridging oxygen as confirmed by the predominance of $\mathrm{Q}^{1}$ groups. This is a satisfying verification since one of the fundamental aspects to the hydrogen absorption ability of these glasses, is the existence of a large number of non-bridging oxygen in their structure. Besides the pyrophosphate groups, the structure of these glasses is mainly composed by structural units related to the character of niobium as network former or modifier.

The Raman spectrum of the A-Li glass reveals the appearance of a few new bands, but it's also perceptible that some of the discussed

Table 4

Physical parameters obtained by the Differential Thermal Analysis (DTA) conducted to $\mathrm{A}-(\mathrm{Li}, \mathrm{Na}, \mathrm{K})$ samples. The maximum uncertainty is $7 \%$.

\begin{tabular}{lllllll}
\hline Glass & $\mathrm{T}_{\mathrm{g}}\left({ }^{\circ} \mathrm{C}\right)$ & $\mathrm{T}_{\mathrm{X} 1}\left({ }^{\circ} \mathrm{C}\right)$ & $\mathrm{T}_{\mathrm{C} 1}\left({ }^{\circ} \mathrm{C}\right)$ & $\mathrm{T}_{\mathrm{C} 2}\left({ }^{\circ} \mathrm{C}\right)$ & $\mathrm{T}_{\mathrm{C} 3}\left({ }^{\circ} \mathrm{C}\right)$ & $\Delta \mathrm{T}=\mathrm{T}_{\mathrm{X} 1}-\mathrm{T}_{\mathrm{g}}$ \\
\hline A-Li & 415 & 483 & 539 & 697 & 804 & 68 \\
1A-Na & 420 & 571 & 584 & - & - & 151 \\
A-K & 412 & 584 & 600 & - & - & 172
\end{tabular}

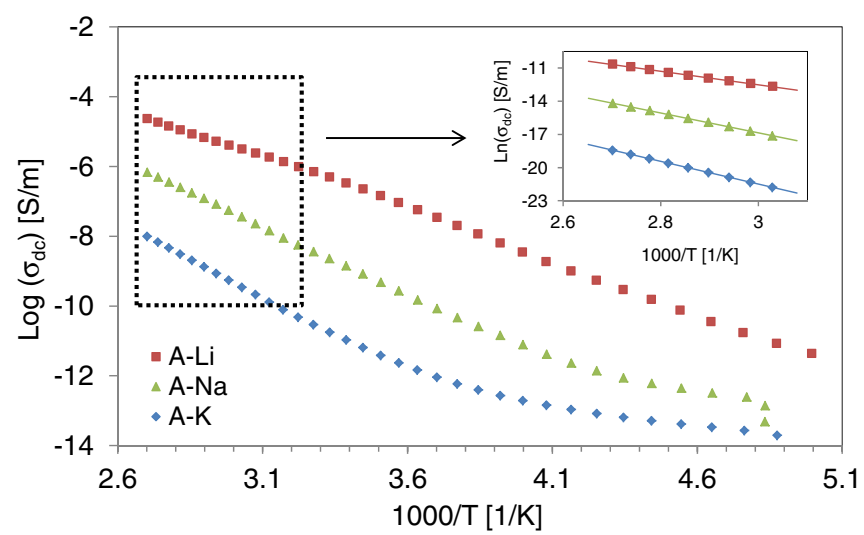

Fig. 5. Dc conductivity (logarithmic scale) versus $1000 / \mathrm{T}$ for all samples ( $5 \%$ is the maximum uncertainty of the measured values). Linearization of their conductivity using the Arrhenius equation in the graphic inset.

bands remain present although they have been slightly shifted. The Raman band position and assignment of the vibrational modes of the A-Li sample are shown in Table 3 . The band at $850 \mathrm{~cm}^{-1}$ assigned to the vibrations of $\mathrm{Nb}$ as network former or modifier, besides being shifted to $884 \mathrm{~cm}^{-1}$ suffers a significant decrease in its intensity, and the band centered at $950 \mathrm{~cm}^{-1}$ in the A- $(\mathrm{Na}, \mathrm{K})$ spectra shifts to $960 \mathrm{~cm}^{-1}$ in the A-Li spectrum.

Another perceptible change in A-Li Raman spectrum is the disappearance of the bands centered at 608/606, 922/910 and 1036/ $1035 \mathrm{~cm}^{-1}$ registered in the A-( $\left.\mathrm{Na}, \mathrm{K}\right)$ samples, which leads us to assume that there is an absence of orthoborate groups and a decrease of non-bridging oxygen in the A-Li glass structure. There are however, some new bands that arise, namely at $125 \mathrm{~cm}^{-1}$ probably related to $\delta(\mathrm{P}-\mathrm{O}-\mathrm{P})[21]$ and/or to $\delta(\mathrm{O}-\mathrm{M}-\mathrm{O})$ of $\mathrm{MO}_{6}(\mathrm{M}=\mathrm{W}, \mathrm{Nb})[3]$, and at $327 \mathrm{~cm}^{-1}$ a band assigned to $\delta(\mathrm{O}-\mathrm{P}-\mathrm{O})$ of $\mathrm{PO}_{4}$ units [38] and/or bending vibrations of $\mathrm{WO}_{6}$ octahedron [39].

The most intense vibrations of the Raman spectrum of this sample are located in the $550-800 \mathrm{~cm}^{-1}$ region. At approximately $710 \mathrm{~cm}^{-1}$ there is a band assigned to the symmetric stretching mode of $\mathrm{P}-\mathrm{O}-\mathrm{P}$ bridging bond in $Q^{1}$ groups [27,37], and the $726 \mathrm{~cm}^{-1}$ band is related to $\mathrm{B}-\mathrm{O}-\mathrm{B}$ vibrational modes in chain-type metaborate groups $[32,40]$. Since these are the predominant bands of the spectrum, we can assume that the network structure of the A-Li sample is mainly constituted by $\mathrm{Q}^{1}$ groups and metaborate $\mathrm{BO}_{3}$ units. Another evident change in the Raman spectrum of this sample, is the decrease of the intensity of the band assigned with $\mathrm{P}-\mathrm{O}-\mathrm{P}$ bending.

It is known that vitreous $\mathrm{B}_{2} \mathrm{O}_{3}$ presents a structure of linked triangles forming planar rings (boroxol rings) and that the addition of network modifiers to the $\mathrm{B}_{2} \mathrm{O}_{3}$ matrix can result in tetrahedral boron formation. The absence of bands centered at $770 \mathrm{~cm}^{-1}, 930 \mathrm{~cm}^{-1}$ and $808 \mathrm{~cm}^{-1}$ indicates that tetraborate, triborate, and boroxol rings groups are not detected in the present structures [12]. Moreover, the Raman analysis of the studied samples revealed the formation of orthoborate or chaintype metaborate groups. This supports the conclusion that the portion of $\mathrm{B}_{2} \mathrm{O}_{3}$ and alkali oxides included in these compositions do not promote the formation of $\mathrm{BO}_{4}$ tetrahedra as observed on some other borate glass systems.

Table 5

Values of dc conductivity $\left(\sigma_{\mathrm{dc}}\right)$ at $300 \mathrm{~K}$, and dc activation energy $\left(\mathrm{E}_{\mathrm{a}(\mathrm{dc})}\right)$ calculated by the Arrhenius equation.

\begin{tabular}{|c|c|c|}
\hline & $\sigma_{\mathrm{dc}}$ & $\mathrm{E}_{(\mathrm{a}(\mathrm{dc}))}$ \\
\hline & $(\mathrm{S} / \mathrm{m})$ & $(\mathrm{kJ} / \mathrm{mol}) \mid \mathrm{eV}$ \\
\hline A-Li & $4.90 \times 10^{-7} \pm 0.61 \times 10^{-7}$ & $57.76 \pm 0.37 \mid 0.599 \pm 0.004$ \\
\hline $\mathrm{A}-\mathrm{Na}$ & $2.25 \times 10^{-9} \pm 0.11 \times 10^{-9}$ & $74.52 \pm 0.41 \mid 0.772 \pm 0.004$ \\
\hline A-K & $1.77 \times 10^{-11} \pm 0.16 \times 10^{-11}$ & $85.61 \pm 0.10 \mid 0.887 \pm 0.001$ \\
\hline
\end{tabular}




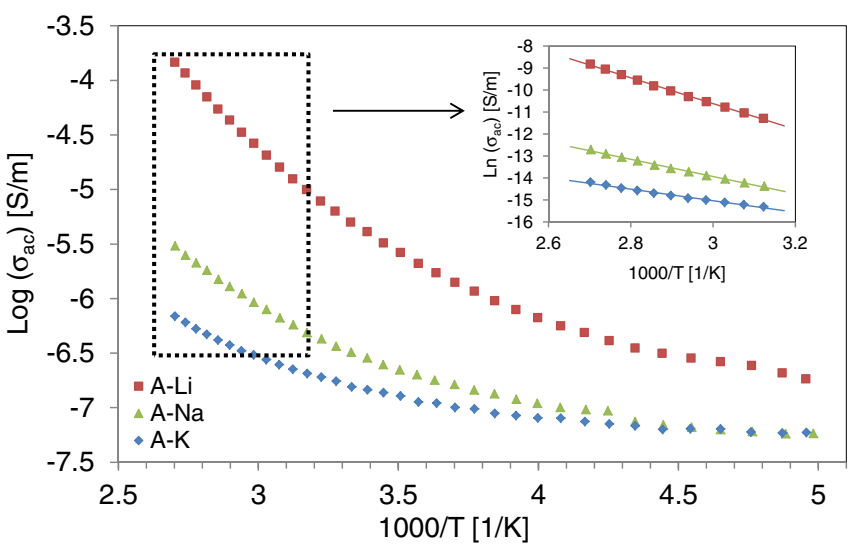

Fig. 6. Ac conductivity (logarithmic scale) versus $1000 / \mathrm{T}$ for all samples (4\% is the maximum uncertainty). Linearization of their conductivity using the Arrhenius equation in the graphic inset.

In order to discern the structural units responsible for each vibrational mode, further study of these compositions as function of the molar percentage of $\mathrm{Nb}_{2} \mathrm{O}_{5} \mathrm{WO}_{3}$ and $\mathrm{B}_{2} \mathrm{O}_{3}$ should be considered.

\subsection{Morphological characterization}

The obtained SEM micrographs (Fig. 3) showed that, both A-Na and A-K have a very smooth and homogenous surface without evidence of particle formation in their surfaces. Whereas the SEM image of A-Li glass surface reveals the presence of structural units with a parallelepiped shape, impregnated in the amorphous matrix as suggested from the XRD results. The distribution of these units through the glass matrix does not present an orientation preference. Analyzing the SEM micrograph of the A-Li sample, one can see that the linear dimensions of the parallelepiped units are approximately $1.5 \mu \mathrm{m}$ (length) and $250 \mathrm{~nm}$ (width). In all samples Energy Dispersive X-ray Spectroscopy (EDS) was performed in order to verify the existence of contaminants. The information obtained, confirm the inexistence of elements different from those of each sample composition.

\subsection{Differential thermal analysis}

The DTA spectra of the glasses are shown in Fig. 4. Typical glass parameters: $\mathrm{Tg}$ (glass transition temperature), Tx (the onset of crystallization temperature), and Tc (crystallization temperature) were extracted from these curves and are summarized in Table 4. For the A-(Na, K) samples, the DTA spectra reveals the existence of a single crystallization at around $600{ }^{\circ} \mathrm{C}$, while for the A-Li glass three broad exothermic peaks are visible, related to the formation of at least, three crystalline phases in its network by heating.

The values of the glass transition temperature of the samples are very similar, being more detectable variations on the crystallization temperature of the glasses, resulting from the different alkali oxides used in the studied compositions. The relatively high glass transition temperatures of these samples allow them, thermally, to be used as electrolytes in intermediate temperatures fuel cells. For the evaluation of the thermal stability of glasses, the $\Delta \mathrm{T}=\mathrm{T}_{\mathrm{X} 1}-\mathrm{Tg}$ criterion was applied. Higher values of this criterion usually correspond to a higher thermal stability and glass-forming ability. The obtained values of $\Delta \mathrm{T}$ for the studied glasses are given in Table 4. The A-Li composition led to the formation of a glass ceramic sample with an amorphous phase besides the two crystalline phases, as previously discussed on the XRD results. The existence of an amorphous phase on this sample, allows the determination of its $\mathrm{Tg}$ in the same way as on the $\mathrm{A}-(\mathrm{Na}, \mathrm{K})$ glasses. The obtained value of $\Delta \mathrm{T}=68$ for the A-Li glass, is smaller than the $\Delta \mathrm{T}$ measured on the remaining samples. This means that the A-Li sample has lower thermal stability, and a higher crystallization tendency that can be achieved for instance, through heat treatments.

\subsection{Electrical measurements}

Fig. 5 depicts the logarithm of $\sigma_{\mathrm{dc}}$ as function of the inverse of the temperature for all the prepared glasses. For the A-( $\mathrm{Na}, \mathrm{K})$ samples it is possible to identify two distinct conduction regimes, one in the low temperature measurement range $(<250 \mathrm{~K})$ and another in the high temperature range.

Since the activation energy at lower temperatures is very small ( $\approx 3 \mathrm{~kJ} / \mathrm{mol}$ ), the dc conductivity at this range of temperatures can be assigned to electron and/or polaronic hopping between different oxidation states of the tungsten cation $[41,42]$, namely the $\mathrm{W}^{5+}$ and $\mathrm{W}^{6+}$ states. Niobium ions can also have difference oxidation states $\left(\mathrm{Nb}^{4+}\right.$ and $\left.\mathrm{Nb}^{5+}\right)$, and although for most glasses the predominant state is $\mathrm{Nb}^{5+}$ (related to the formation of $\mathrm{NbO}_{6}$ structural units), in some phosphate glasses niobium ions can change their coordination state, which enables them to act as network former or modifier [43]. For that matter, not only the tungsten cations, but also the niobium ions can contribute to the electronic conductivity.

On the high temperature regime, both electronic and ionic conductivity coexist, but the total conductivity is ruled by the ionic contribution assigned to the non-random hopping of the modifier cations. For the A-Li glass, a different scenario is observed in the $\sigma_{\mathrm{dc}}$ plot. The total conductivity is not characterized by two different conduction regimes, but seems instead to follow a linear evolution with the temperature variation. This could be explained by a predominance of the ionic conductivity at the entire temperature range evaluated, meaning that even though at lower temperatures there might also exist an electronic contribution to the conductivity, it is very small compared to the ionic contribution.

Comparing the three samples, it is perceptible that in the entire temperature measurement range, the conductivity increases significantly (about two orders of magnitude) with the decrease of the alkali cation mass and radius, which is an expected result since the ionic mobility increases with the decrease of the referred properties.

Arrhenius formalism was applied as plotted in the inset of Fig. 5, to determine the activation energy (Table 5) of the glasses at higher temperatures. As expected, the activation energy increases with the increase of the alkali cation mass, according to their mobility. The preexponential factor $\sigma_{0}$ that appears on the linearization of the Arrhenius equation, depends on the average distance between the charge carriers and the neighboring anions which they interact with, and also on the number and vibration frequency of the charge carriers.

Based on the obtained values of $\sigma_{0}$, we can conclude that there is a higher number of charge carriers in the A- $(\mathrm{Na}, \mathrm{K})$ samples $\left(\sigma_{0}\right.$ of about $\left.10^{4}\right)$. For the A-Li sample, $\sigma_{0}$ is about $10^{2}$ which could be related

Table 6

Values of ac conductivity $\left(\sigma_{\mathrm{ac}}\right)$, ac activation energy $\left(\mathrm{E}_{\mathrm{a}(\mathrm{ac})}\right)$, dielectric constant $\left(\varepsilon^{\prime}\right)$ and loss tangent $(\tan \delta)$ at $300 \mathrm{~K}$ and $10 \mathrm{kHz}$

\begin{tabular}{|c|c|c|c|c|}
\hline & $\begin{array}{l}\sigma_{\mathrm{ac}} \\
(\mathrm{S} / \mathrm{m})\end{array}$ & $\begin{array}{l}\mathrm{E}_{(\mathrm{a}(\mathrm{ac}))} \\
(\mathrm{kJ} / \mathrm{mol}) \mid \mathrm{eV}\end{array}$ & $\varepsilon^{\prime}$ & $\begin{array}{l}\tan \delta \\
\left(\times 10^{-2}\right)\end{array}$ \\
\hline A-Li & $5.00 \times 10^{-6} \pm 0.19 \times 10^{-6}$ & $48.77 \pm 0.65 \mid 0.506 \pm 0.007$ & $33.89 \pm 2.28$ & $26.52 \pm 2.06$ \\
\hline $\mathrm{A}-\mathrm{Na}$ & $3.22 \times 10^{-7} \pm 0.05 \times 10^{-7}$ & $32.65 \pm 0.64 \mid 0.338 \pm 0.007$ & $15.95 \pm 1.33$ & $3.63 \pm 0.31$ \\
\hline A-K & $1.55 \times 10^{-7} \pm 0.03 \times 10^{-7}$ & $21.91 \pm 0.70 \mid 0.227 \pm 0.007$ & $29.46 \pm 1.28$ & $0.94 \pm 0.04$ \\
\hline
\end{tabular}


to the formation of $\mathrm{Li}_{0.585} \mathrm{NbO}_{3}$ particles, as this reduces the number of charge carriers that can diffuse freely through the glass network. Nevertheless, since the mobility of the lithium ions is significantly higher than the sodium and potassium ions, the A-Li glass is still the one with higher conductivity values.

Since the electronic conductivity of the A-(Na, K) glasses dominates only at low temperatures, if we consider the conductivity value from the A-K glass $\sigma_{\mathrm{dc}}=1.95 \times 10^{-14}(\mathrm{~S} / \mathrm{m})$ at $200 \mathrm{~K}$ as an approximation of its electronic conductivity value ( $\sigma_{\text {electronic }}$ ) and $\sigma_{\mathrm{dc}}$ at $300 \mathrm{~K}$ $\left(1.77 \times 10^{-11} \mathrm{~S} / \mathrm{m}\right)$ as the value of its ionic conductivity $\left(\sigma_{\text {ionic }}\right)$, we can measure the ratio $\sigma_{\text {electronic }} / \sigma_{\text {ionic }}$ which is about $10^{-3}$. For mixed conductive amorphous materials, that simultaneously exhibit ionic and electronic conductivity, the determination of this ratio can be an elementary evaluation of the electronic conductivity contribution. Considering this evaluation, both A-K and A-Na $\left(\sigma_{\text {electronic }} / \sigma_{\text {ionic }}\right.$ about $10^{-5}$ ) samples can have their dc conductivity considered as purely ionic. This is a meaningful result since one of the requirements for the success of these glasses as fuel cell electrolytes, is that they should have a significantly reduced electronic conductivity. This acknowledgment combined with the Raman results which reported a predominance of pyrophosphate groups, allows the assumption that the structure of these glasses is favorable for the mobility of charge carriers as ions and protons.

Fig. 6 shows the dependency of the logarithm of $\sigma_{\mathrm{ac}}$ with the inverse of the temperature. Contrarily to the dc conductivity, it's not easy to discern two different conduction mechanisms due to the absence of a clear inflection point. The conductivity mechanism should be related to a dipolar mechanism between the modifier ions and the non-bridging oxygen anions in their vicinity.

In order to determine the activation energy of the conductivity at high temperature region, the linearization of $\sigma_{\mathrm{ac}}$ was made according with the Arrhenius equation, and plotted in the inset of Fig. 6 . The values of the activation energy (Table 6 ) follow the opposite trend observed in the $\sigma_{\mathrm{dc}}$. For the ac conductivity, the activation energy of the glass A$\mathrm{K}<\mathrm{A}-\mathrm{Na}<\mathrm{A}$-Li, but the conductivity of the samples does not increase with the decrease of the activation energy. This could be associated with the number of charge carriers available for the ac conductivity on each sample. Analyzing the pre-exponential factor $\left(\sigma_{0}\right)$ of the ac conductivity of each sample, we can see that in fact for the A-K sample $\sigma_{0}$ is 2 orders of magnitude smaller than $\sigma_{0}$ from the A-Na glass, and 4 orders of magnitude smaller than $\sigma_{0}$ from A-Li sample. This explains that, although the activation energy of the A-K glass is the smallest one out of the three samples, there is not a significantly high number of free charge carriers that could contribute to the conductivity process.

The dependency of $\varepsilon^{\prime}$ with the applied frequency for the prepared samples, at $300 \mathrm{~K}$, is shown in Fig. 7. For the samples A-K and A-Na this quantity is practically independent of the measured frequency, whereas for sample A-Li increases significantly for lower frequencies.

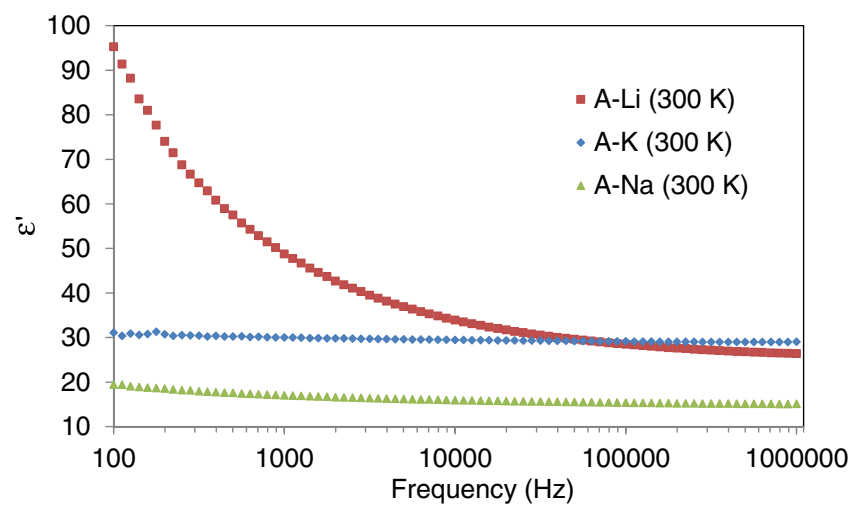

Fig. 7. Dielectric constant versus frequency, at $300 \mathrm{~K}$, for all samples (maximum uncertainty $7 \%$ ).

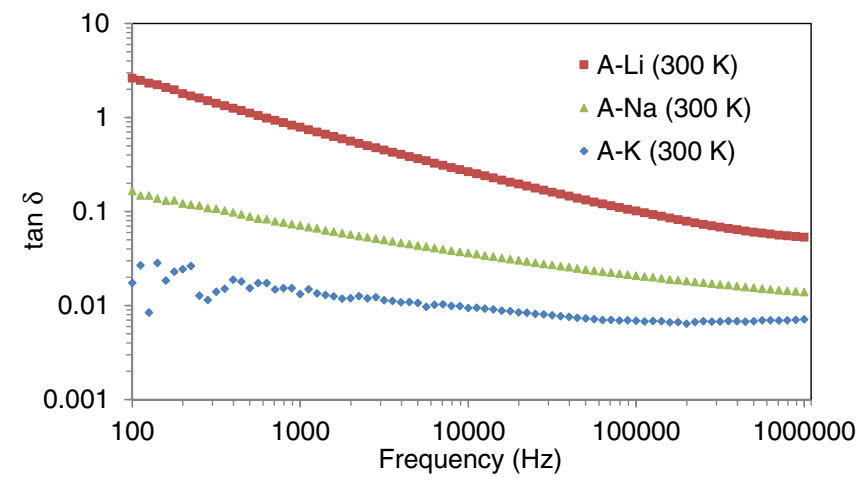

Fig. 8. Loss tangent versus frequency, at $300 \mathrm{~K}$, for all samples (maximum uncertainty $8 \%$ ).

This behavior is due to charge accumulation effects at the interfaces amorphous matrix-crystalline structural units $[44,45]$. For higher frequencies, A-Li and A-K tend to the same $\varepsilon^{\prime}$ value, while A-Na exhibits a smaller value, suggesting that the latter has a smaller number of electric dipoles.

Fig. 8 shows the loss tangent $(\tan \delta$ ) as a function of the measurement frequency, at $300 \mathrm{~K}$. Sample A-K has the lowest loss tangent, while sample A-Li possesses significant losses, being the highest conductive sample.

The A-( $\mathrm{Li}, \mathrm{Na}$ ) glasses revealed the existence of dielectric relaxations as shown in Fig. 9. Using the dielectric modulus formalism [14], it is clear the evolution of a thermally activated relaxation peak, which shifts towards higher frequencies with the increase of the temperature. For the A-Na sample these relaxation peaks are not visible in the $\varepsilon^{\prime \prime}$
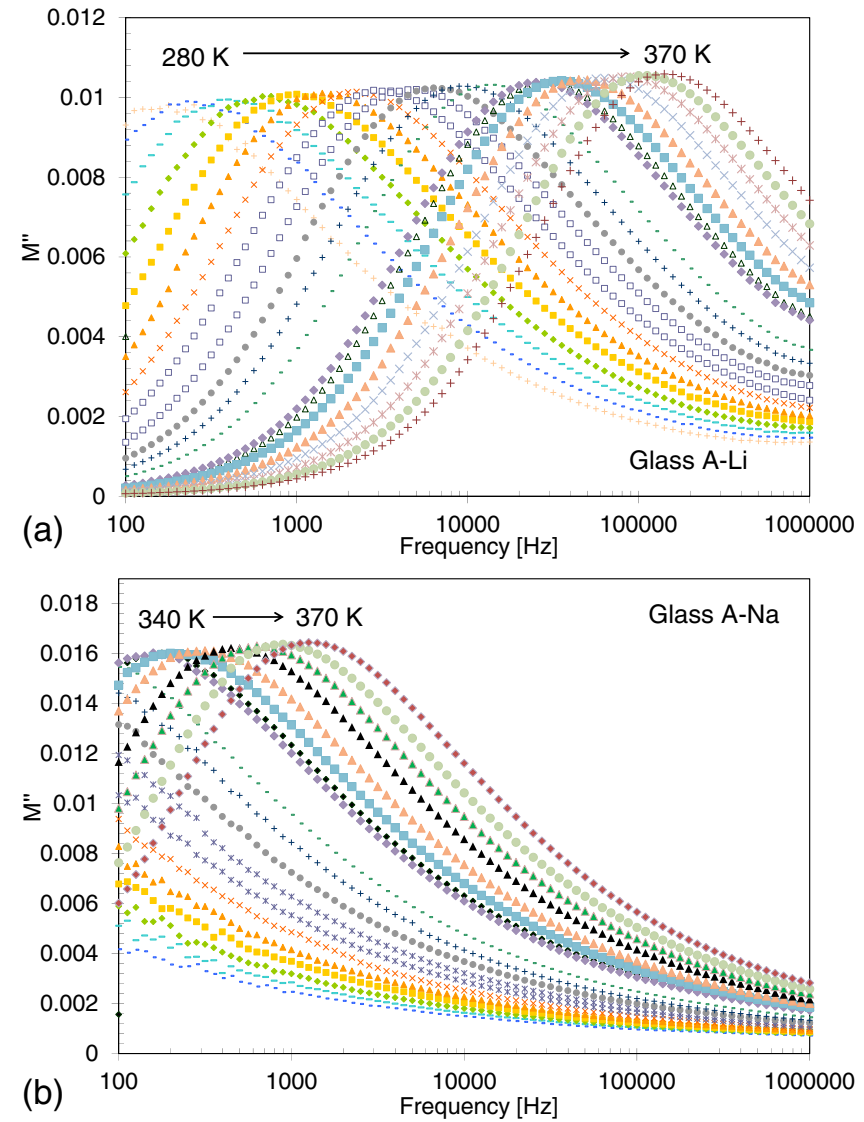

Fig. 9. $\mathrm{M}^{\prime \prime}$ versus frequency, at several temperatures, for the A-Li (a) and A-Na (b) samples (maximum uncertainty $7 \%$ ). 

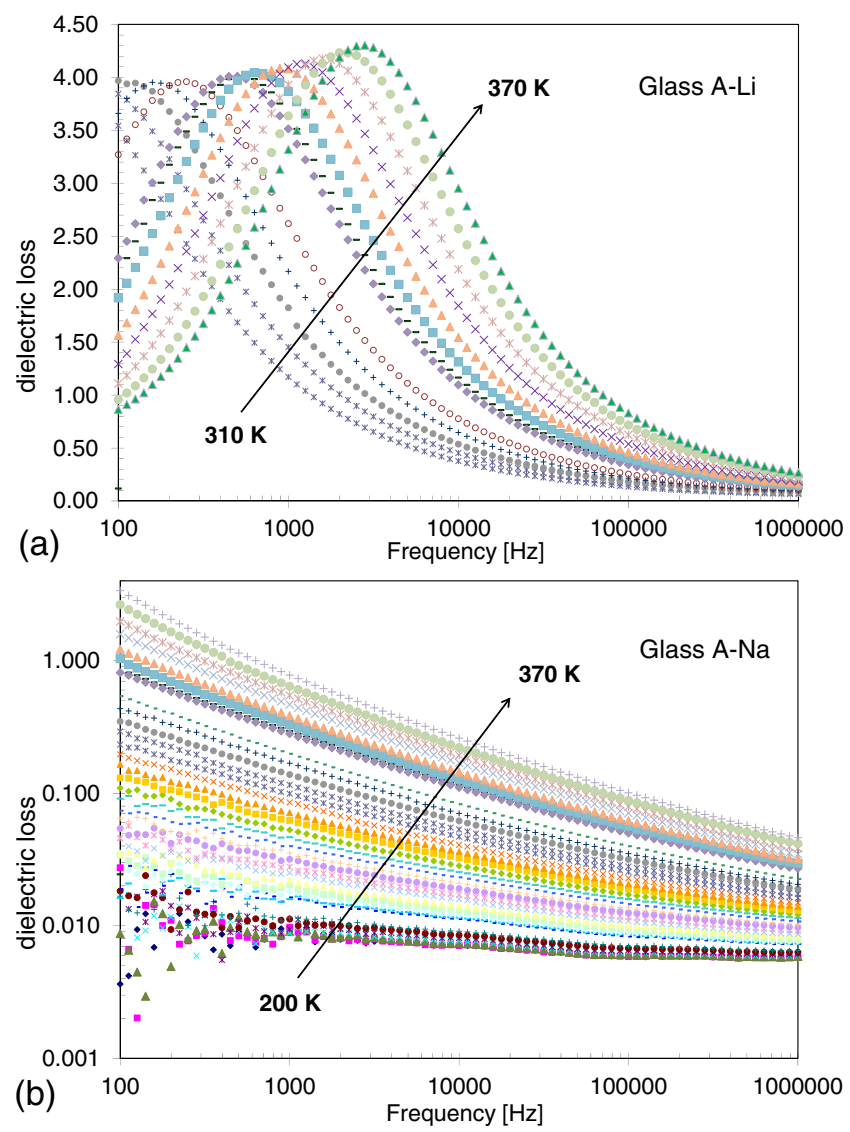

Fig. 10. Dielectric loss versus frequency, at $300 \mathrm{~K}$, for the A-Li (a) and A-Na (b) samples (maximum uncertainty $4 \%$ ).
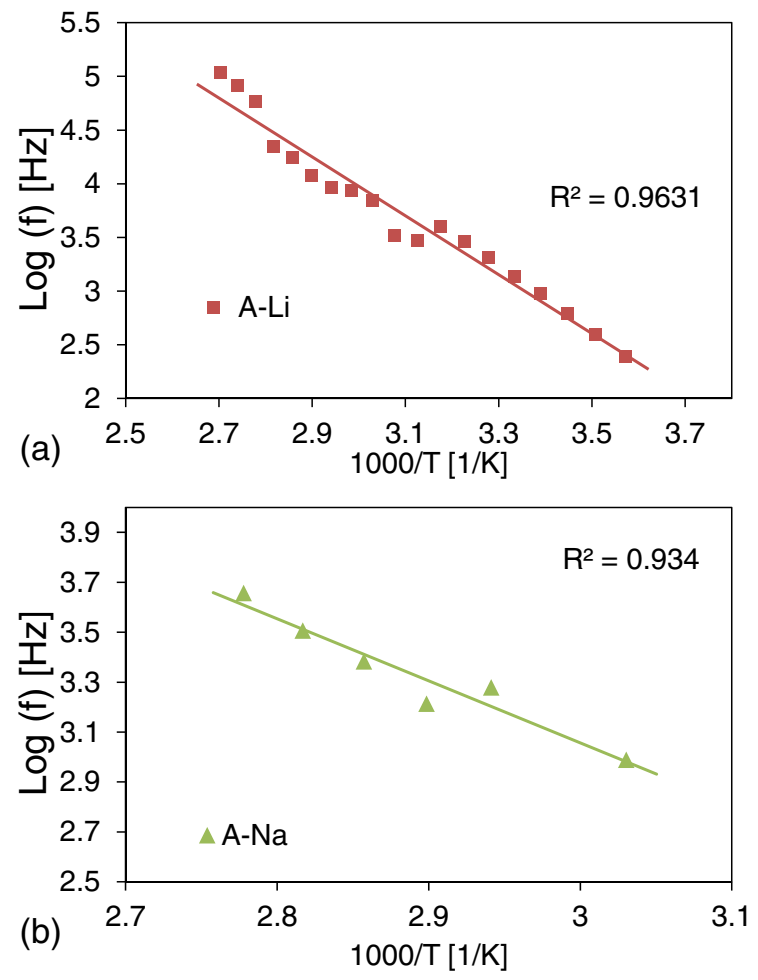

Fig. 11. Logarithm of relaxation frequency versus $1000 / \mathrm{T}$, for the A-Li (a) and A-Na (b) samples. representation (Fig. 10). The complex dielectric modulus ( $\left.\mathrm{M}^{\prime \prime}\right)$ formulation is often used to study the dielectric properties of glasses with a high degree of ionic conductivity, since it has the advantage of minimize high capacitance effects due to spatial charge accumulation [46]. These peaks were fitted according the Havriliak-Negami dielectric relaxation model using Winfit software from Novocontrol, in order to determine their relaxation times.

The relaxation kinetics was found to be described by an Arrhenius dependency (Fig. 11) in the evaluated temperature range, with activation energies of $52.5 \mathrm{~kJ} / \mathrm{mol}$ for sample A-Li and $47.7 \mathrm{~kJ} / \mathrm{mol}$ for sample A-Na. The similarity between the conductivity and relaxation activation energies in the A-Li sample, might indicate that the mechanism responsible for the $\sigma_{\mathrm{ac}}$ may be similar to the mechanism of the relaxation.

\section{Conclusions}

Functional phosphate glasses with molar composition $20.7 \mathrm{P}_{2} \mathrm{O}_{5}-$ $17.2 \mathrm{Nb}_{2} \mathrm{O}_{5}-13.8 \mathrm{WO}_{3}-34.5 \mathrm{~A}_{2} \mathrm{O}-13.8 \mathrm{~B}_{2} \mathrm{O}_{3}$ (where $\mathrm{A}=\mathrm{Li}, \mathrm{Na}, \mathrm{K}$ ) were prepared by melt quenching technique. The compositions containing $\mathrm{Na}_{2} \mathrm{O}$ and $\mathrm{K}_{2} \mathrm{O}$ led to the formation of transparent glasses, whereas the composition with $\mathrm{Li}_{2} \mathrm{O}$ resulted in a glass ceramic material.

The XRD results showed an amorphous structure for the A- $(\mathrm{Na}$, $\mathrm{K})$ samples, and for $\mathrm{A}-\mathrm{Li}$ the formation of two crystalline phases ( $\mathrm{Li}_{0.585} \mathrm{NbO}_{3}$ and $\mathrm{Nb}_{26} \mathrm{~W}_{4} \mathrm{O}_{77}$ ) in coexistence with the amorphous phase, which was confirmed by the SEM micrographs.

The samples A-( $\mathrm{Na}, \mathrm{K})$ presented a similar Raman spectrum and according with the identified vibrational modes, their network structure is mainly composed by pyrophosphate and orthoborate groups, and also by structural units where niobium acts as network former or modifier. On the other hand, the Raman spectrum of the A-Li sample revealed some distinct bands, and its analysis showed that its network might be mostly constituted by pyrophosphate and metaborate $\mathrm{BO}_{3}$ groups. The predominance of the $\mathrm{Q}^{1}$ groups indicates that there is a large number of non-bridging oxygen in the glass structure, available to bond with hydrogen protons. Also, the relatively high glass transition temperatures $\left(412-420^{\circ} \mathrm{C}\right)$ of these samples allow them to operate as electrolytes in intermediate temperatures fuel cells.

The A-Li glass revealed predominantly ionic dc conductivity at the entire evaluated temperature range. While for the $\mathrm{A}-(\mathrm{Na}, \mathrm{K})$ samples can be identified by two distinct dc conduction regimes, one in the low temperature measurement range $(<250 \mathrm{~K})$ and another in the high temperature range. The conductivity in the low temperature regime is assigned to electron hopping between different oxidation states of the tungsten and niobium cations, while for high temperatures is assigned to the non-random hopping of the modifier cations. The activation energy increases with the increase of the alkali cation mass, according with their mobility. According with the $\sigma_{\text {electronic }} / \sigma_{\text {ionic }}$ ratio, the dc conductivity of these two samples can likewise be assumed as purely ionic, which is also a fundamental aspect for the application of these glasses as fuel cell electrolytes.

The ac conductivity mechanism of the samples may be related to a dipolar mechanism between the modifier ions and the non-bridging oxygen anions in their vicinity.

Regarding the dielectric measurements, for the samples A-K and A-Na, $\varepsilon^{\prime}$ is practically constant at the evaluated frequency range, whereas for sample A-Li increases significantly for lower frequencies. This behavior is due to the contribution of charge accumulation effects at the interfaces amorphous matrix-crystalline structural units. For the samples $\mathrm{A}-\mathrm{Li}$ and $\mathrm{A}-\mathrm{Na}$, according the dielectric modulus formalism it is clear the evolution of a thermally activated relaxation peak, which shifts towards higher frequencies with the increase of the temperature. The relaxation kinetics was found to be described by an Arrhenius dependency, with activation energies of $52.5 \mathrm{~kJ} / \mathrm{mol}$ for sample A-Li and $47.7 \mathrm{~kJ} / \mathrm{mol}$ for sample A-Na. The similarity for the A-Li sample, between the conductivity and relaxation activation energies indicates that the 
mechanism responsible for $\sigma_{\mathrm{ac}}$ may be similar to the mechanism of the relaxation.

\section{Acknowledgments}

The authors are grateful to the Fundação para a Ciência e Tecnologia (FCT) for the financial support offered to this work (RECI/FIS-NAN/ 0183/2012 FCOMP-01-124-FEDER-027494, and Pest-C/CTM/LA0025/ 2013-14).

\section{References}

[1] R.K. Brow, Review: the structure of simple phosphate glasses, J. Non-Cryst. Solids 263-264 (2000) 1-28.

[2] D. Di Tommaso, R.I. Ainsworth, E. Tang, N.H. de Leeuw, Modelling the structural evolution of ternary phosphate glasses from melts to solid amorphous materials, J. Mater. Chem. B 1 (38) (2013) 5054-5066.

[3] L. Bih, M. Azrour, B. Manoun, M.P.F. Graça, M.A. Valente, Raman spectroscopy, X-Ray, SEM, and DTA analysis of alkali-phosphate glasses containing and $\mathrm{Nb}_{2} \mathrm{O}_{5}, \mathrm{~J}$ Spectrosc. 2013 (2013) 10.

[4] T. Ishiyama, J. Nishii, T. Yamashita, H. Kawazoe, T. Omata, Electrochemical substitution of sodium ions with protons in phosphate glass to fabricate pure proton conducting glass at intermediate temperatures, J. Mater. Chem. A. 2 (11) (2014) 3940-3947.

[5] S. Mizusaki, Y. Toyoda, K. Nakayama, Y. Nagata, T.C. Ozawa, Y. Noro, H. Samata Catalysis and proton-conduction of novel phosphate glasses, J. Non-Cryst. Solids 355 (16-17) (2009) 960-964.

[6] K. Nakayama, M.J. Nishi, T. Taniguchi, S. Mizusaki, Y. Nagata, T.C. Ozawa, Y. Noro, H. Samata, Catalysts for hydrogen generation from water vapor, Sci. Technol. Adv. Mater. 7 (1) (2006) 52-55.

[7] M.A. Valente, L. Bih, M.P.F. Graça, Dielectric analysis of tungsten-phosphoniobate $20 \mathrm{~A}_{2} \mathrm{O}-30 \mathrm{WO}_{3}-10 \mathrm{Nb}_{2} \mathrm{O}_{5}-40 \mathrm{P}_{2} \mathrm{O}_{5}(\mathrm{~A}=\mathrm{Li}, \mathrm{Na})$ glass-ceramics, J. Non-Cryst. Solids 357 (1) (2011) 55-61.

[8] H. Doweidar, Consideration of the boron oxide anomaly, J. Mater. Sci. 25 (1) (1990) 253-258.

[9] D.R. Uhlmann, R.R. Shaw, The thermal expansion of alkali borate glasses and the boric oxide anomaly, J. Non-Cryst. Solids 1 (5) (1969) 347-359.

[10] J.E. Shelby, Introduction to glass science and technology, 2nd Edition The Royal Society of Chemistry, UK, 2005.

[11] C.C. de Araujo, W. Strojek, L. Zhang, H. Eckert, G. Poirier, S.J.L. Ribeiro, Y. Messaddeq, Structural studies of $\mathrm{NaPO}_{3}-\mathrm{WO}_{3}$ glasses by solid state NMR and Raman spectroscopy, J. Mater. Chem. 16 (32) (2006) 3277-3284.

[12] M.P.F. Graça, M.G.F.d Silva, M.A. Valente, Influence of thermal and thermoelectric treatments on structure and electric properties of $\mathrm{B}_{2} \mathrm{O}_{3}-\mathrm{Li}_{2} \mathrm{O}-\mathrm{Nb}_{2} \mathrm{O}_{5}$ glasses, J. Non Cryst. Solids 354 (10-11) (2008) 901-908.

[13] J. Belattar, M.P.F. Graça, L.C. Costa, M.E. Achour, C. Brosseau, Electric modulus-based analysis of the dielectric relaxation in carbon black loaded polymer composites, Journal of Applied Physics 107 (12) (2010) 6.

[14] C.C. Silva, M.A. Valente, M.P.F. Graça, A.S.B. Sombra, The modulus formalism used in the dielectric analysis of hydroxyapatite and calcium phosphate with titanium formed by dry ball milling, J. Non-Cryst. Solids 351 (33-36) (2005) 2945-2950.

[15] J.R. Macdonald, Impedance Spectroscopy: Emphasizing Solid Materials and Analysis, John Wiley \& Sons, New York, 1987.

[16] K.J. Rao, Structural Chemistry of Glasses, Elsevier, 2002.

[17] M.M.R.A. Lima, R.C.C. Monteiro, M.P.F. Graça, M.G. Ferreira da Silva, Structural, electrical and thermal properties of borosilicate glass-alumina composites, J. Alloys Compd. 538 (2012) 66-72.

[18] R.L. Frost, Y. Xi, R. Scholz, F.M. Belotti, M.C. Filho, Infrared and Raman spectroscopic characterization of the carbonate mineral weloganite $-\mathrm{Sr}_{3} \mathrm{Na}_{2} \mathrm{Zr}\left(\mathrm{CO}_{3}\right)_{6} \cdot 3 \mathrm{H}_{2} \mathrm{O}$ and in comparison with selected carbonates, J. Mol. Struct. 1039 (2013) 101-106.

[19] J. Čejka, J. Sejkora, I. Jebavá, Y. Xi, S.J. Couperthwaite, R.L. Frost, A Raman spectroscopic study of the basic carbonate mineral callaghanite $\mathrm{Cu}_{2} \mathrm{Mg}_{2}\left(\mathrm{CO}_{3}\right)(\mathrm{OH})_{6} \cdot 2 \mathrm{H}_{2} \mathrm{O}$, Spectrochim. Acta A Mol. Biomol. Spectrosc. 108 (2013) 171-176.

[20] G. Falgayrac, S. Sobanska, C. Brémard, Raman diagnostic of the reactivity between $\mathrm{ZnSO}_{4}$ and $\mathrm{CaCO}_{3}$ particles in humid air relevant to heterogeneous zinc chemistry in atmosphere, Atmos. Environ. 85 (2014) 83-91.
[21] J.J. Hudgens, R.K. Brow, D.R. Tallant, S.W. Martin, Raman spectroscopy study of the structure of lithium and sodium ultraphosphate glasses, J. Non-Cryst. Solids $223(1-2)(1998)$ 21-31.

[22] I. Mazali, L. Barbosa, O. Alves, Preparation and characterization of new niobophosphate glasses in the $\mathrm{Li}_{2} \mathrm{O}-\mathrm{Nb}_{2} \mathrm{O}_{5}-\mathrm{CaO}-\mathrm{P}_{2} \mathrm{O}_{5}$ system, J. Mater. Sci. 39 (6) (2004) 1987-1995.

[23] N. Krishna Mohan, G. Sahaya Baskaran, N. Veeraiah, Dielectric and spectroscopic properties of $\mathrm{PbO}-\mathrm{Nb}_{2} \mathrm{O}_{5}-\mathrm{P}_{2} \mathrm{O}_{5}: \mathrm{V}_{2} \mathrm{O}_{5}$ glass system, Phys. Status Solidi A 203 (8) (2006) 2083-2102.

[24] L. Sirleto, M.G. Donato, G. Messina, S. Santangelo, A.A. Lipovskii, D.K. Tagantsev, S. Pelli, G.C. Righini, Raman gain in niobium-phosphate glasses, Appl. Phys. Lett. 94 (3) (2009).

[25] M.P.F. Graça, M.A. Valente, M.G. Ferreira Da Silva, The electric behavior of a lithiumniobate-phosphate glass and glass-ceramics, J. Mater. Sci. 41 (4) (2006) 1137-1144.

[26] J. Schneider, S.L. Oliveira, L.A.O. Nunes, H. Panepucci, Local structure of sodium aluminum metaphosphate glasses, J. Am. Ceram. Soc. 86 (2) (2003) 317-324.

[27] R.K. Brow, D.R. Tallant, S.T. Myers, C.C. Phifer, The short-range structure of zinc polyphosphate glass, J. Non-Cryst. Solids 191 (1-2) (1995) 45-55.

[28] J. Koo, B.-S. Bae, H.-K. Na, Raman spectroscopy of copper phosphate glasses, J. NonCryst. Solids 212 (2-3) (1997) 173-179.

[29] J.S. de Andrade, A.G. Pinheiro, I.F. Vasconcelos, M.A.B. de Araújo, M.A. Valente, A.S.B. Sombra, Structural studies of $\mathrm{KNbO}_{3}$ in niobate glass-ceramics, J. Phys. Chem. Solids 61 (6) (2000) 899-906.

[30] R.C.C. Figueira, M.P.F. Graça, L.C. Costa, M.A. Valente, Crystallization of $\mathrm{KNbO}_{3}$ in a $\mathrm{B}_{2} \mathrm{O}_{3}$ glass network, J. Non-Cryst. Solids 354 (47-51) (2008) 5162-5164.

[31] V. Kamalaker, G. Upender, C. Ramesh, V. Chandra Mouli, Raman spectroscopy, thermal and optical properties of $\mathrm{TeO}_{2}-\mathrm{ZnO}-\mathrm{Nb}_{2} \mathrm{O}_{5}-\mathrm{Nd}_{2} \mathrm{O}_{3}$ glasses, Spectrochim. Acta A Mol. Biomol. Spectrosc. 89 (2012) 149-154.

[32] L. Singh, V. Thakur, R. Punia, R.S. Kundu, A. Singh, Structural and optical properties of barium titanate modified bismuth borate glasses, Solid State Sci. 37 (2014) 64-71.

[33] B.P. Dwivedi, B.N. Khanna, Cation dependence of raman scattering in alkali borate glasses, J. Phys. Chem. Solids 56 (1) (1995) 39-49.

[34] A.A. Ahmed, N.A. Sharaf, R.A. Condrate Sr., Raman microprobe investigation of sulphur-doped alkali borate glasses, J. Non-Cryst. Solids 210 (1) (1997) 59-69.

[35] S. Zheng, Y. Zhou, D. Yin, X. Xu, Y. Qi, S. Peng, The $1.53 \mu \mathrm{m}$ spectroscopic properties and thermal stability in $\mathrm{Er}^{3+} / \mathrm{Ce}^{3+}$ codoped $\mathrm{TeO}_{2}-\mathrm{WO}_{3}-\mathrm{Na}_{2} \mathrm{O}-\mathrm{Nb}_{2} \mathrm{O}_{5}$ glasses, J. Quant. Spectrosc. Radiat. Transf. 120 (2013) 44-51.

[36] R. Jose, Y. Ohishi, Enhanced Raman gain coefficients and bandwidths in P2O5 and WO3 added tellurite glasses for Raman gain media, Appl. Phys. Lett. 89 (12) (2006).

[37] A. Moguš-Milanković, A. Šantić, A. Gajović, D.E. Day, Spectroscopic investigation of $\mathrm{MoO}_{3}-\mathrm{Fe}_{2} \mathrm{O}_{3}-\mathrm{P}_{2} \mathrm{O}_{5}$ and $\mathrm{SrO}-\mathrm{Fe}_{2} \mathrm{O}_{3}-\mathrm{P}_{2} \mathrm{O}_{5}$ glasses, part I, J. Non Cryst. Solids 325 (1-3) (2003) 76-84.

[38] Y.M. Lai, X.F. Liang, S.Y. Yang, J.X. Wang, B.T. Zhang, Raman spectra study of iron phosphate glasses with sodium sulfate, J. Mol. Struct. 1013 (2012) 134-137.

[39] D. Manzani, R.G. Fernandes, Y. Messaddeq, S.J.L. Ribeiro, F.C. Cassanjes, G. Poirier, Thermal, structural and optical properties of new tungsten lead-pyrophosphate glasses, Opt. Mater. 33 (12) (2011) 1862-1866.

[40] C. Gejke, E. Zanghellini, J. Swenson, L. Börjesson, Microscopic structure of tin-borate and tin-boratephosphate glasses, J. Power Sources 119-121 (2003) 576-580.

[41] G. Upender, C. Sameera Devi, V. Chandra Mouli, Role of $\mathrm{WO}_{3}$ on DC conductivity and some optical properties of $\mathrm{TeO}_{2}$ based glasses, Mater. Res. Bull. 47 (11) (2012) 3764-3769.

[42] J.C. Bazan, J.A. Duffy, M.D. Ingram, M.R. Mallace, Conductivity anomalies in tungstatephosphate glasses: evidence for an ion-polaron interaction? Solid State Ionics 86-88 (Part 1) (1996) 497-501.

[43] S. Sanghi, A. Sheoran, A. Agarwal, S. Khasa, Conductivity and dielectric relaxation in niobium alkali borate glasses, Phys. B Condens. Matter 405 (24) (2010) 4919-4924.

[44] D. Rollik, S. Bauer, R. Gerhard-Multhaupt, Separate contributions to the pyroelectricity in poly(vinylidene fluoride) from the amorphous and crystalline phases, as well as from their interface, J. Appl. Phys. 85 (6) (1999) 3282-3288.

[45] H. Ghamlouche, S.T. Mahmoud, N. Qamhieh, Electrical properties of $\mathrm{Se}_{2} \mathrm{Sb}_{2} \mathrm{Te}_{6}$ thin films, J. Phys. D. Appl. Phys. 41 (21) (2008) 215303.

[46] M.V.N.V.D. Sharma, A.V. Sarma, R.B. Rao, Electrical characterization and relaxation behavior of lithium-indium-phosphate glasses via impedance spectroscopy, Turk. J. Phys. 33 (2009) 87-100.

[47] T. Harada, H. In, H. Takebe, K. Morinaga, Effect of $\mathrm{B}_{2} \mathrm{O}_{3}$ addition on the thermal stability of barium phosphate glasses for optical fiber devices, J. Am. Ceram. Soc. 87 (3) (2004) 408-411. 